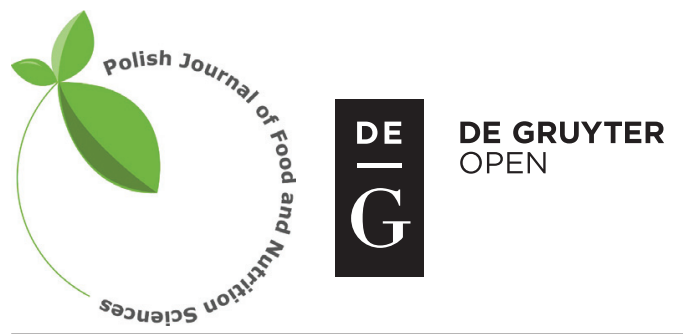

Pol. J. Food Nutr. Sci., 2017, Vol. 67, No. 4, pp. 275-281

DOI: $10.1515 /$ pjfns-2017-0016 http://journal.pan.olsztyn.pl

Original research article

Section: Food Quality and Functionality

\title{
Colour Stability and Lipid Oxidation of Beef Longissimus Lumborum under Different Packaging Conditions
}

\author{
Dadji Stéphane Serge Bonny, Xin Li*, Zheng Li, Meng Li, Manting Du, Lingling Gao, Dequan Zhang*
}

Institute of Food Science and Technology, Chinese Academy of Agricultural Sciences/Key Laboratory of Agro-Products
Processing, Ministry of Agriculture, No. I Nongda South Rd., Xi Beiwang, Haidian District, Beijing 100193, PR China

Key words: beef, vacuum, modified atmosphere packaging, colour, lipid oxidation

The objective of this study was to investigate the colour stability and lipid oxidation of beef under different packaging methods. The muscles longissimus lumborum were randomly packed in vacuum or modified atmosphere packaging (MAP, $80 \% \mathrm{O}_{2}, 20 \% \mathrm{CO}_{2}$ ). Both packages were aged at $4^{\circ} \mathrm{C}$ for 7 , 14 and 21 days. After each ageing time, samples were displayed in a refrigerator for 2, 4 and 6 days. Colour stability, lipid oxidation and their correlation were determined. Beef under vacuum packaging showed higher a* values on 7, 14, and 21 days of ageing and lower L* values on 14 and 21 days of ageing than beef in MAP $(p<0.05)$. Lower $a^{*}$ values were observed in the samples packed in MAP, then displayed compared to samples packed in vacuum, then displayed after 21 days of ageing time on day 2, 4 and 6 of the display period $(\mathrm{p}<0.05)$. Thiobarbituric acid reactive substances (TBARS) increased significantly in MAP compared to vacuum during 7, 14, and 21 days of ageing $(\mathrm{p}<0.05)$. An increase of TBARS was also observed during display after 14 and 21 days of ageing in samples packed in MAP, then displayed. Furthermore, a significant difference $(\mathrm{p}<0.05)$ was observed between samples packed in MAP and vacuum in peroxide value on 14 days of ageing. Lipid oxidation was observed mainly in the samples packed in MAP compared to vacuum, and positively correlated with results on colour stability.

\section{INTRODUCTION}

One of the most important quality criteria that consumers look for when purchasing meat and meat products is colour. The change in meat colour from red to brown may be rejected by consumers as it appears to be unhealthy. As a result, meat discoloration leads to an important financial loss to the retailer and the industry [Beriain et al., 2009]. Meat is full of muscles which contain myoglobin, the primary red pigment in meat [AMSA, 2012]. There are other proteins that play a role in beef colour, which are heme proteins known as haemoglobin and cytochrome $\mathrm{C}$ [Mancini \& Hunt, 2005]. Many factors such as animal genetics, age, packaging methods, storage time, temperature, $\mathrm{pH}$ and the quantity of unsaturated fatty, affect meat colour [AMSA, 2012].

During the storage and processing of foods, polyunsaturated fatty acid are subject to oxidation [Hęś, 2017]. Unsaturated fatty acids and oxygen involvement in lipid oxidation creates unstable intermediates that give an unpleasant flavour and aroma compounds when breakdown [Akoh \& Min, 2008]. Thus, lipid oxidation is one of the major phenomenon which leads to quality deterioration in muscle foods

\footnotetext{
* Corresponding Author: Tel.: +86-10-62818740

E-mail: dequan_zhang0118@126.com (Dequan ZHANG, PhD, Professor) Email:xinli.caas@gmail.com (Xin LI, PhD, Assistant Professor)
}

during storage [Akoh \& Min, 2008]. Moreover, the interaction of lipid oxidation byproducts, such as malondialdehyde and 4-hydroxyl nonenal, with proteins and DNA may lead to biological damage [Li \& Liu, 2012]. Colour and lipid oxidation are important factors for the consumer to accept fresh meat [Jakobsen \& Bertelsen, 2000].

Previously reported studies have focused on colour stability and packaging system [Jeong \& Claus, 2010; Lindahl, 2011; Li et al., 2012, 2014; Kang et al., 2014; Strydom \& Hope-Jones, 2014], to demonstrate that packaging methods greatly influence the meat colour. However, lipid oxidation and its effect on fresh meat colour have been another interesting issue which has extensively been researched on. For example, Jakobsen \& Bertelsen [2000] developed mathematical models that describe the relationship between discolouration and lipid oxidation in beef, however their conclusions were limited because of biological differences between the animals. Vitale et al. [2014] evaluated the effects of ageing time in vacuum on colour and lipid oxidation of beef during display in MAP. Against this background and in view of the previous findings, it is evident that improvement of meat colour can be considered as a challenge for meat scientists and the meat industry.

The objective of the present study was to determine the effect of beef lipid oxidation and colour stability under modified atmosphere packaging (MAP, $80 \% \mathrm{O}_{2}, 20 \% \mathrm{CO}_{2}$ ) and vacuum package during ageing and display in refrigerator. 


\section{MATERIALS AND METHODS}

\section{Sampling and packaging}

Beef longissimus lumborum $(L L)$ muscle samples of $25 \mathrm{~cm}$ length from five males of Holstein breed (age 11-12 months, $\mathrm{pH}_{48} 5.41$ to 5.61) were collected locally from a slaughter plant. The samples were stored at $4^{\circ} \mathrm{C}$ wrapped with clean sterile polyethylene bags and transported immediately to the laboratory. The samples were cut into $2.5 \mathrm{~cm}$ thick slices, and randomly assigned to vacuum packaging or modified atmosphere packaging $\left(80 \% \mathrm{O}_{2}, 20 \% \mathrm{CO}_{2}\right)$ at $48 \mathrm{~h}$ postmortem. The packed samples were stored at $4^{\circ} \mathrm{C}$ for 7,14 and 21 days. After each storage day, the samples were opened from packages for colour analysis, then cut into one third and two thirds. The one third was vacuum packed and kept at $-80^{\circ} \mathrm{C}$ for chemical analysis. The two thirds were overwrapped and then displayed in darkness in a refrigerator at $4{ }^{\circ} \mathrm{C}$ for 2 , 4 and 6 days for further colour analysis and kept at $-80^{\circ} \mathrm{C}$ for chemical analysis.

\section{Colour}

Meat colour was measured using a Chroma meter (CR400 Konica Minolta Sensing Inc., Osaka, Japan). Using the CIELAB system, coordinates L*(lightness), a* (redness), and $\mathrm{b}^{*}$ (yellowness) were measured after calibrating the colour meter on a standard white plate $(\mathrm{Y}=93.9, \mathrm{x}=0.3155$, and $y=0.3318)$. The average value of four measurements was recorded. After corresponding ageing time, the samples packed in vacuum and modified atmosphere packaging were opened, wrapped with a film on a plate and kept at $4^{\circ} \mathrm{C}$ in a refrigerator for colour measurement. Measurements were made directly on the meat surface after being displayed at day 2,4 and 6.

\section{Lipid oxidation}

\section{TBARS}

Lipid oxidation was evaluated by the determination of thiobarbituric acid reactive substances (TBARS) using the extraction method as described by Botsoglou et al. [1994] and Marcos et al. [2007] with minor modifications. Triplicate $3 \mathrm{~g}$ samples were homogenised with $20 \mathrm{~mL}$ of ultrapure water. Five millilitres of $25 \%$ trichloroacetic acid were added to the homogenate and centrifuged at $4^{\circ} \mathrm{C}$ for $15 \mathrm{~min}$ at $10,000 \times \mathrm{g}$. The supernatant obtained was filtrated through a filter paper. The solution $(3.5 \mathrm{~mL}$ of the extract) was pipetted into a test tube and $1.5 \mathrm{~mL}$ of $0.6 \%$ aqueous 2-thiobarbituric acid was added. The solution was kept in a water bath at $70^{\circ} \mathrm{C}$ for $30 \mathrm{~min}$ and then cooled in tap water for $10 \mathrm{~min}$. The resulting colour was measured with the Spectra Max 340 PC (Molecular devices DANAHER) at $532 \mathrm{~nm}$ to calculate the TBARS value. The results were expressed as mg malondialdehyde $/ \mathrm{kg}$ of meat.

\section{Lipid extraction}

Lipid extraction was performed according to Gheisari \& Eskandari [2013] with some modifications. About $5 \mathrm{~g}$ of samples were weighed, minced, and homogenised with $50 \mathrm{~mL}$ of chloroform/methanol $(2: 1 \mathrm{v} / \mathrm{v})$ for $1 \mathrm{~min}$ at $10,000 \mathrm{rpm}$.
A solution of $12.5 \mathrm{~mL}$ of $1 \mathrm{mmol} / \mathrm{L}$ of $\mathrm{CaCl}_{2}$ was added to the sample tubes. Samples were centrifuged at $1000 \mathrm{rpm}$ and $10^{\circ} \mathrm{C}$ for $20 \mathrm{~min}$. The chloroform phase was dried by rotary evaporation. Chloroform/methanol $2 \times 2 \mathrm{~mL}$ and $2 \mathrm{~mL}$ of $\mathrm{CaCl}_{2}$ were added to the dried sample, vortex-mixed and put in test tubes, and centrifuged at $2500 \mathrm{rpm}$ for $20 \mathrm{~min}$. The lipid phase was removed, dried by nitrogen evaporator and weighed.

\section{Peroxide value $(P V)$}

The method described by Shantha \& Decker [1994], and Soyer et al. [2010] was used to determine the peroxide values. The extracted lipid samples $(\leq 0.01-0.30 \mathrm{~g})$ were mixed with $9.8 \mathrm{~mL}$ of chloroform-methanol $(7+3, \mathrm{v} / \mathrm{v})$ in a disposable glass tube and vortex-mixed for 2-4 s. An ammonium thiocyanate solution $(0.05 \mathrm{~mL})$ was added, and the sample was vortex-mixed for $2-4 \mathrm{~s}$. an iron (II) solution $(0.05 \mathrm{~mL})$ was added and the sample was again vortex-mixed for 2-4 s. After 5 min of incubation at room temperature, the absorbance was measured at $500 \mathrm{~nm}$ against a blank that contained all the reagents except the sample using a spectrophotometer. The results were expressed in milli-equivalents of peroxide per $\mathrm{kg}$ of fat.

\section{Statistical analysis}

Statistical analysis was carried out with SPSS 19.0 statistics software. Independent T-test was done to analyse statistical differences between treatments. Data analysis of colour parameters, TBARS, and PV during ageing period and display period was performed using one-way ANOVA for comparison of means between packaging methods. The effect of ageing period, packaging type and interaction of those variables on colour and lipid oxidation parameters were analysed using ANOVA. The Pearson's linear correlation coefficient was applied to study the relationship between variables during ageing. Results were expressed by means \pm standard deviation.

\section{RESULTS}

\section{Colour}

Results of instrumental measurements of colour parameters $\left(\mathrm{L}^{*}, \mathrm{a}^{*}\right.$, and $\left.\mathrm{b}^{*}\right)$ made throughout ageing in each treatment are presented in Table 1. The lowest $\mathrm{L}^{*}$ values were found in vacuum-packed samples after ageing for 14 and 21 days $(p<0.05)$ compared to the MAP-packed ones. It was further observed that $\mathrm{L}^{*}$ values in both packaging methods were increasing as ageing time extended from 7 to 14 days $(\mathrm{p}<0.05)$. In addition, the samples packed in vacuum and MAP had higher $L^{*}$ values $(p<0.05)$ after ageing for 14 days as compared to 7 days. The samples packed under vacuum had higher $a^{*}(p<0.05)$ values than MAP samples after ageing for 7,14 and 21 days. The a* values of MAP samples were significantly affected by ageing time from 7 to 21 days $(\mathrm{p}<0.05)$. Redness ( $a^{*}$ ) did not differ significantly after 14 days of ageing compared to 21 days ageing $(p>0.05)$ in the vacuum-packed samples. A significant difference $(p<0.05)$ was observed after ageing for 21 days on $b^{*}$ values in the samples packed in MAP compared to those packed in vacuum. The $b^{*}$ values were higher in MAP $(p<0.05)$ than in vacuum-packed samples. 
TABLE 1. Effect of treatment (vacuum packaging or MAP $\left(80 \% \mathrm{O}_{2}, 20 \%\right.$ $\left(\mathrm{CO}_{2}\right)$ ) on Lightness ( $\left.\mathrm{L}^{*}\right)$, Redness (a"), Yellowness ( $\left.\mathrm{b}^{*}\right)$ values in beef steak of longissimus lumborum during ageing.

\begin{tabular}{|c|c|c|c|c|}
\hline \multirow{2}{*}{\multicolumn{2}{|c|}{ Package }} & \multicolumn{3}{|c|}{ Ageing time (days) } \\
\hline & & 7 & 14 & 21 \\
\hline \multirow{2}{*}{$\mathrm{L}^{*}$} & Vacuum & $39.94 \pm 2.46^{\mathrm{b}}$ & $45.28 \pm 1.85^{\mathrm{aA}}$ & $42.74 \pm 2.36^{\mathrm{abA}}$ \\
\hline & MAP & $41.65 \pm 2.82^{\mathrm{b}}$ & $48.55 \pm 2.26^{\mathrm{aB}}$ & $50.03 \pm 3.07^{\mathrm{aB}}$ \\
\hline \multirow{2}{*}{$a^{*}$} & Vacuum & $20.27 \pm 1.72^{\mathrm{aA}}$ & $15.55 \pm 1.17^{\mathrm{bA}}$ & $15.48 \pm 1.12^{\mathrm{bA}}$ \\
\hline & MAP & $15.38 \pm 1.95^{\mathrm{aB}}$ & $7.51 \pm 1.40^{\mathrm{bB}}$ & $4.60 \pm 1.23^{\mathrm{cB}}$ \\
\hline \multirow{2}{*}{$b^{*}$} & Vacuum & $10.12 \pm 1.23^{\mathrm{a}}$ & $7.66 \pm 0.95^{\mathrm{b}}$ & $7.59 \pm 0.97^{\mathrm{bA}}$ \\
\hline & MAP & $10.31 \pm 0.95^{\mathrm{a}}$ & $8.13 \pm 1.18^{b}$ & $10.65 \pm 1.69^{\mathrm{aB}}$ \\
\hline
\end{tabular}

Different letters $(a-c)$ for each $L^{*}, a^{*}, b^{*}$ value in the same row are significantly different $(\mathrm{p}<0.05)$.

Different letters (A-B) between vacuum or MAP for each $L^{*}, a^{*}, b^{*}$ value in the same column are significantly different $(p<0.05)$.

A significant interaction was observed for colour parameters in which treatments and ageing period effects were studied $(p<0.05)$. The effect of the interaction of treatments as well as ageing periods was observed on $\mathrm{L}^{*}, \mathrm{a}^{*}$, and $\mathrm{b}^{*}$ values (Table 2 ).

Results of instrumental measurements of colour parameters $\left(L^{*}, a^{*}\right.$, and $\left.b^{*}\right)$ throughout the display period of beef samples packed in vacuum or MAP, then displayed after each ageing time are shown in Table 3. There were no differences observed in $\mathrm{L}^{*}$ values between the samples packed in vacuum or MAP, then displayed on day 2, 4 and 6 after 7 day of ageing $(p>0.05)$. However, significant differences $(p<0.05)$ were observed in $\mathrm{L}^{*}$ values on day 2, 4 and 6 of display time between the samples packed in MAP and vacuum, then displayed after day 21 of ageing. Significant differences $(p<0.05)$ were also found in $\mathrm{L}^{*}$ values of the samples packed in vacuum, then displayed on day 2 of display time compared to day 6 of display after 7 days ageing.

Differences $(\mathrm{p}<0.05)$ in $\mathrm{a}^{*}$ values were observed in the samples packed in MAP, then displayed compared to the samples packed in vacuum, then displayed after 7 days ageing time during day 2 of display time. The same trend of results $(p<0.05)$ was found in the samples packed in MAP, then displayed compared to the samples packed in vacuum, then displayed after 14 days ageing time but during day 2 and 4 of display time.

Significant differences in $b^{*}$ values $(p<0.05)$ were observed in the samples packed in MAP, then displayed on day 6 of display time compared to the samples packed in vacu- um, then displayed after 14 days of ageing. In addition, significant differences $(p<0.05)$ were noted in $b^{*}$ values within the two treatments after 21 days of ageing time on day 2, 4 and 6 of display time with higher $b^{*}$ values in the samples packed in MAP, and then displayed.

\section{Lipid oxidation}

TBARS and peroxide value were used in this study to determine the extent of lipid oxidation that occurred during ageing time and display.

\section{TBARS}

Results for TBARS values of the samples packed in MAP or vacuum for 7, 14 and 21 days of ageing and after display are presented in Table 4. Before display, significant differences $(p<0.05)$ in TBARS were observed between the samples packed in MAP and vacuum after ageing for 7, 14 and 21 days. Results revealed that TBARS were the lowest $(\mathrm{p}<0.05)$ in vacuum compared to MAP samples during ageing. Significant differences $(\mathrm{p}<0.05)$ in TBARS were observed among ageing times in vacuum. In MAP, differences were observed on day 7 of ageing compared to day 14 and 21 of ageing. No effect of interaction of the two-factor treatments and ageing was observed on TBARS values ( $p>0.05$ ) while treatments as well as ageing periods had an effect on TBARS values $(\mathrm{p}<0.05)$.

There were significant differences $(p<0.05)$ between the samples packed in MAP and vacuum and then displayed in TBARS values after ageing for 14 and 21 days followed by display period. The TBARS values of the samples packed with both methods increased with an increase of ageing time.

\section{Peroxide value $(P V)$}

Results for peroxide values of the samples packed in MAP or vacuum for 7, 14 and 21 days of ageing and after display are shown in Table 4. Before display, a significant difference $(p<0.05)$ was found in PV between the samples packed in MAP and vacuum after ageing for 14 days. A significant difference $(p<0.05)$ in PV was also noted during ageing time and after display in the samples packed in vacuum, then displayed. Results further revealed that PV mean values in the samples packed in MAP, then displayed increased significantly $(\mathrm{p}<0.05)$ after 14 days of ageing. Any interaction of the two-factor treatments, and ageing was observed on PV values ( $p>0.05)$.

\section{Correlation analysis}

Pearson's coefficients of correlation determined between lipid oxidation parameters (TBARS, peroxides) and colour

TABLE 2. Factors affecting colour stability.

\begin{tabular}{|c|c|c|c|c|c|c|c|c|c|c|c|}
\hline \multirow{2}{*}{ Variable } & \multirow{2}{*}{ df } & \multicolumn{2}{|c|}{$\mathrm{L}^{*}$} & \multicolumn{2}{|c|}{$a^{*}$} & \multicolumn{2}{|c|}{$b^{*}$} & \multicolumn{2}{|c|}{ TBARS } & \multicolumn{2}{|c|}{ PV } \\
\hline & & SS & $\operatorname{Pr}>\mathrm{F}$ & SS & $\operatorname{Pr}>\mathrm{F}$ & SS & $\operatorname{Pr}>\mathrm{F}$ & SS & $\operatorname{Pr}>\mathrm{F}$ & SS & $\operatorname{Pr}>F$ \\
\hline Independent treatment $(\mathrm{T})$ & 1 & 125.440 & * & 472.529 & $*$ & 11.504 & * & 67.288 & * & 0.004 & ns \\
\hline Ageing (A) & 2 & 229.852 & * & 341.698 & $*$ & 26.782 & * & 44.719 & $*$ & 0.003 & ns \\
\hline $\mathrm{T}^{*} \mathrm{~A}$ & 2 & 41.300 & $*$ & 44.970 & $*$ & 12.441 & $*$ & 1.682 & ns & 0.002 & ns \\
\hline
\end{tabular}

$*(p<0.05)$, ns: no significant differences $(p>0.05)$. 
TABLE 3. L*, a* $\mathrm{b}^{*}$ values of beef steak of longissimus lumborum stored under vacuum packaging or MAP $\left(80 \% \mathrm{O}_{2}, 20 \% \mathrm{CO}_{2}\right)$ then displayed in a refrigerator after different ageing times.

\begin{tabular}{|c|c|c|c|c|}
\hline \multirow{2}{*}{$\begin{array}{l}\text { Ageing } \\
\text { time } \\
\text { (days) }\end{array}$} & \multirow{2}{*}{ package } & \multicolumn{3}{|c|}{ Display time (days) } \\
\hline & & 2 & 4 & 6 \\
\hline \multicolumn{5}{|c|}{$\mathrm{L}^{*}$} \\
\hline \multirow{2}{*}{7} & Vacuum & $40.03 \pm 2.47^{\mathrm{a}}$ & $38.45 \pm 4.42^{\mathrm{ab}}$ & $34.80 \pm 2.53^{b}$ \\
\hline & MAP & $42.32 \pm 3.30^{\mathrm{a}}$ & $40.15 \pm 2.45^{\mathrm{ab}}$ & $37.57 \pm 3.49^{b}$ \\
\hline \multirow{2}{*}{14} & Vacuum & $44.78 \pm 2.52$ & $45.32 \pm 2.42$ & $44.43 \pm 2.89$ \\
\hline & MAP & $47.19 \pm 2.43$ & $47.82 \pm 2.48$ & $46.69 \pm 2.21$ \\
\hline \multirow{2}{*}{21} & Vacuum & $42.86 \pm 1.54^{\mathrm{A}}$ & $43.39 \pm 2.30^{\mathrm{A}}$ & $42.23 \pm 1.85^{\mathrm{A}}$ \\
\hline & MAP & $49.62 \pm 1.27^{\mathrm{B}}$ & $48.85 \pm 1.16^{\mathrm{B}}$ & $47.82 \pm 1.43^{\mathrm{B}}$ \\
\hline \multicolumn{5}{|c|}{$a^{*}$} \\
\hline \multirow{2}{*}{7} & Vacuum & $20.83 \pm 2.69^{\mathrm{aA}}$ & $14.26 \pm 3.56^{\mathrm{b}}$ & $12.21 \pm 3.36^{\mathrm{b}}$ \\
\hline & MAP & $11.13 \pm 2.59^{\mathrm{B}}$ & $11.68 \pm 1.51$ & $10.80 \pm 1.64$ \\
\hline \multirow{2}{*}{14} & Vacuum & $16.43 \pm 1.02^{\mathrm{aA}}$ & $12.55 \pm 2.70^{\mathrm{bA}}$ & $7.27 \pm 0.99^{c}$ \\
\hline & MAP & $5.85 \pm 1.89^{\mathrm{abB}}$ & $4.95 \pm 1.03^{\text {вв }}$ & $5.72 \pm 1.93^{\mathrm{ab}}$ \\
\hline \multirow{2}{*}{21} & Vacuum & $16.42 \pm 1.12^{\mathrm{aA}}$ & $11.00 \pm 3.59^{\mathrm{bA}}$ & $9.72 \pm 1.57^{\mathrm{bA}}$ \\
\hline & MAP & $4.15 \pm 0.50^{\text {в }}$ & $4.19 \pm 0.47^{\mathrm{B}}$ & $4.76 \pm 1.05^{\mathrm{B}}$ \\
\hline \multicolumn{5}{|c|}{$b^{*}$} \\
\hline \multirow{2}{*}{7} & Vacuum & $11.51 \pm 1.61^{\mathrm{aA}}$ & $8.30 \pm 2.60^{b}$ & $5.53 \pm 1.51^{\mathrm{c}}$ \\
\hline & MAP & $9.86 \pm 0.95^{\mathrm{abB}}$ & $8.25 \pm 2.24^{b}$ & $10.80 \pm 1.64$ \\
\hline \multirow{2}{*}{14} & Vacuum & $8.89 \pm 0.80^{\mathrm{a}}$ & $8.06 \pm 0.66^{\mathrm{ab}}$ & $6.58 \pm 0.95^{\mathrm{cA}}$ \\
\hline & MAP & $9.60 \pm 1.83$ & $9.63 \pm 1.53$ & $8.76 \pm 1.29^{\mathrm{B}}$ \\
\hline \multirow{2}{*}{21} & Vacuum & $8.71 \pm 0.68^{\mathrm{aA}}$ & $7.87 \pm 0.59^{\mathrm{abA}}$ & $6.30 \pm 1.69^{\mathrm{bA}}$ \\
\hline & MAP & $10.90 \pm 1.92^{\mathrm{B}}$ & $10.59 \pm 1.75^{\mathrm{B}}$ & $10.94 \pm 1.63^{\text {в }}$ \\
\hline
\end{tabular}

Different letters $(a-c)$ for each $L^{*}, a^{*}, b^{*}$ value in the same row are significantly different $(\mathrm{p}<0.05)$.

Different letters (A-B) between vacuum or MAP, for each $L^{*}, a^{*}, b^{*}$ value at each ageing time in the same column are significantly different $(p<0.05)$. ns: no significant differences $(p>0.05)$.

parameters in vacuum- and MAP-packed samples are shown in Table 5. Significant correlations $(p<0.01)$ were found between lipid oxidation parameters mainly for TBARS and colour parameters with high correlations between TBARS and $L^{*}, a^{*}$ and $b^{*}$ values in the samples packed in vacuum. Similarly, a significant $(\mathrm{p}<0.05)$ correlation was found in MAP samples between TBARS and $\mathrm{L}^{*}, \mathrm{a}^{*}$ values.

\section{DISCUSSION}

In the present study, L* values in both packaging methods increased as ageing time extended from 7 to 14 days. Furthermore, it was observed that meat aged in vacuum had lower $\mathrm{L}^{*}$ values compared to meat aged in MAP during 14 and 21 days of ageing. This observation is in agreement with findings of Insausti et al. [1999] who reported that beef packed under vacuum had lower $\mathrm{L}^{*}$ value than that under modified atmosphere
TABLE 4. Lipid oxidation expressed as TBARS (mg of malonaldehyde/ $\mathrm{kg}$ meat) and peroxide values (milliequivalent of peroxide $/ \mathrm{kg}$ ) in aged beef steak of longissimus lumborum stored under vacuum packaging or MAP before and after display in a refrigerator.

\begin{tabular}{|c|c|c|c|}
\hline \multirow{2}{*}{ Package } & \multicolumn{3}{|c|}{ Ageing time (days) } \\
\hline & 7 & 14 & 21 \\
\hline \multicolumn{4}{|c|}{ TBARS } \\
\hline \multicolumn{4}{|c|}{ Before display } \\
\hline Vacuum & $0.59 \pm 0.26^{\mathrm{cA}}$ & $2.49 \pm 0.32^{\mathrm{bA}}$ & $2.87 \pm 0.25^{\mathrm{aA}}$ \\
\hline MAP & $3.00 \pm 1.53^{\mathrm{bB}}$ & $5.50 \pm 1.34^{\mathrm{aB}}$ & $6.44 \pm 0.59^{\mathrm{aB}}$ \\
\hline \multicolumn{4}{|c|}{ After display } \\
\hline Vacuum & $4.35 \pm 1.45$ & $4.17 \pm 0.76^{\mathrm{A}}$ & $3.62 \pm 0.25^{A}$ \\
\hline MAP & $5.81 \pm 2.20^{\mathrm{b}}$ & $6.13 \pm 072^{\mathrm{bB}}$ & $8.23 \pm 1.10^{\mathrm{aB}}$ \\
\hline \multicolumn{4}{|c|}{ PV } \\
\hline \multicolumn{4}{|c|}{ Before display } \\
\hline Vacuum & $0.04 \pm 0.03$ & $0.04 \pm 0.03^{\mathrm{A}}$ & $0.05 \pm 0.04$ \\
\hline MAP & $0.05 \pm 0.03$ & $0.09 \pm 0.03^{\mathrm{B}}$ & $0.07 \pm 0.04$ \\
\hline \multicolumn{4}{|c|}{ After display } \\
\hline Vacuum & $0.02 \pm 0.01^{\mathrm{c}}$ & $0.05 \pm 0.02^{\mathrm{b}}$ & $0.08 \pm 0.03^{\mathrm{a}}$ \\
\hline MAP & $0.02 \pm 0.01^{\mathrm{b}}$ & $0.05 \pm 0.02^{\mathrm{b}}$ & $0.10 \pm 0.04^{\mathrm{a}}$ \\
\hline
\end{tabular}

Different letters $(\mathrm{a}-\mathrm{c})$ for each TBARS and PV value in the same row are significantly different $(\mathrm{p}<0.05)$. Different letters $(A-B)$ between vacuum or MAP for each TBARS and PV value in the same column are significantly different $(\mathrm{p}<0.05)$.

$\left(60 \% \mathrm{O}_{2}, 30 \% \mathrm{CO}_{2}\right.$ and $\left.10 \% \mathrm{~N}_{2}\right)$. In addition, Insausti et al. [1999] observed this effect as the storage time increased. Similar results on lower $\mathrm{L}^{*}$ value u vacuum-packed beef were also pointed out by Li et al. [2012] although in this case the storage time was short. Similarly, Kim et al. [2014] reported also an increase of $\mathrm{L}^{*}$ values but in pork samples stored in MAP with 20 and $70 \%$ oxygen respectively while the vacuum-packed samples remained constant. In this study, as ageing time increased, it impacted the $\mathrm{L}^{*}$ values which simultaneously increased in both packaging methods. This situation may be explained by the relative oxygen consumption of the meat during ageing. In a related study, Esmer et al. [2011] investigated the effects of modified atmosphere gas compositions on colour properties ( $\mathrm{L}^{*}, \mathrm{a}^{*}$ and $\mathrm{b}^{*}$ values) and found out that $\mathrm{L}^{*}$ values were significantly affected by the storage time. Ageing period and the interaction between treatments and ageing period had a significant effect on $a^{*}$ values. Samples packed in vacuum were found to have higher a* values than samples packed in MAP after ageing for 7, 14 and 21 days. In addition, $\mathrm{a}^{*}$ values stayed steadfast in vacuum after 14 and 21 days of ageing while in MAP they decreased significantly after ageing for 7 to 21 days. The higher $a^{*}$ value registered in our study in vacuum packaging compared to MAP during ageing might be attributed to the rapid decrease of oxygen in MAP as ageing time increased. In fact, a higher oxygen content (80\%) in MAP contributed to the oxygenation of myoglobin but in our study, after one-week storage, the sample packed in MAP became 
TABLE 5. Pearson's correlations amongst colour parameters $\left(\mathrm{L}^{*}, \mathrm{a}^{*}, \mathrm{~b}^{*}\right)$ and oxidation indexes (TBARS and peroxide value) in beef steak of longissimus lumborum stored under vacuum packaging or MAP and aged for 7, 14 and 21 days.

\begin{tabular}{|c|c|c|c|c|c|c|}
\hline Parameters & & $\mathrm{L}^{*}$ & $a^{*}$ & $b^{*}$ & TBARS & PV \\
\hline \multicolumn{7}{|c|}{ MAP } \\
\hline \multirow{2}{*}{$\mathrm{L}^{*}$} & Pearson Correlation & 1.000 & $-0.881^{* *}$ & 0.220 & $0.721^{*}$ & 0.469 \\
\hline & Sig. (2-tailed) & & $<0.001$ & 0.431 & 0.002 & 0.078 \\
\hline \multirow{2}{*}{$a^{*}$} & Pearson Correlation & $-0.881^{* *}$ & 1.000 & 0.029 & $-0.851^{* *}$ & -0.389 \\
\hline & Sig. (2-tailed) & $<0.001$ & & 0.919 & $<0.001$ & 0.152 \\
\hline \multirow{2}{*}{$b^{*}$} & Pearson Correlation & 0.220 & 0.029 & 1.000 & -0.051 & -0.021 \\
\hline & Sig. (2-tailed) & 0.431 & 0.919 & & 0.857 & 0.940 \\
\hline \multirow{2}{*}{ TBARS } & Pearson Correlation & $0.721^{* * *}$ & $-0.851^{* *}$ & -0.051 & 1.000 & 0.453 \\
\hline & Sig. (2-tailed) & 0.002 & $<0.001$ & 0.857 & & 0.090 \\
\hline \multirow{2}{*}{ PV } & Pearson Correlation & 0.469 & -0.389 & -0.021 & 0.453 & 1.000 \\
\hline & Sig. (2-tailed) & 0.078 & 0.152 & 0.940 & 0.090 & \\
\hline \multicolumn{7}{|c|}{ Vacuum } \\
\hline \multirow{2}{*}{$\mathrm{L}^{*}$} & Pearson Correlation & 1.000 & -0.417 & -0.260 & $0.651^{* *}$ & $0.515^{*}$ \\
\hline & Sig. (2-tailed) & & 0.122 & 0.350 & 0.009 & 0.049 \\
\hline \multirow{2}{*}{$a^{*}$} & Pearson Correlation & -0.417 & 1.000 & $0.950^{*}$ & $-0.772^{* *}$ & -0.097 \\
\hline & Sig. (2-tailed) & 0.122 & & $<0.001$ & 0.001 & 0.730 \\
\hline \multirow{2}{*}{$b^{*}$} & Pearson Correlation & -0.260 & $0.950^{* *}$ & 1.000 & $-0.689^{* *}$ & 0.084 \\
\hline & Sig. (2-tailed) & 0.350 & $<0.001$ & & 0.004 & 0.765 \\
\hline \multirow{2}{*}{ TBARS } & Pearson Correlation & $0.651^{* *}$ & $-0.772^{* *}$ & $-0.689^{* *}$ & 1.000 & 0.181 \\
\hline & Sig. (2-tailed) & 0.009 & 0.001 & 0.004 & & 0.518 \\
\hline \multirow{2}{*}{ PV } & Pearson Correlation & $0.515^{*}$ & -0.097 & 0.084 & 0.181 & 1.000 \\
\hline & Sig. (2-tailed) & 0.049 & 0.730 & 0.765 & 0.518 & \\
\hline
\end{tabular}

* Correlation is significant at the 0.05 level (2-tailed); ${ }^{* *}$ Correlation is significant at the 0.01 level (2-tailed).

brown on the surface compared to the vacuum-packed sample. Our results are consistent with previous findings of Kang et al. [2014] who reported on a rapidly decreased a* value in beef stored under MAP, with limited changes during storage in the beef packed under vacuum. High metmyoglobin percentage was also observed at the surface of meat packed under modified atmosphere after 15 days of storage, together with the decrease that was observed in redness [Insausti et al., 1999]. These findings are consistent with our results, which have been demonstrated by the decrease in a* value during ageing in MAP. Though, a high metmyoglobin percentage (brown colour at the surface of the meat) is related to the ageing time. However, Faustman et al. [2010] found out that the decrease in red colour was caused by oxidation of oxymyoglobin to metmyoglobin and lipid oxidation increases this phenomenon. Metal ions (iron, copper) could also stimulate the colour change through the formation of metmyoglobin under aerobic conditions [AMSA, 2012].

$\mathrm{L}^{*}, \mathrm{a}^{*}$ and $\mathrm{b}^{*}$ values were assessed to determine meat colour stability during display for 2, 4 and 6 days after 7,14 and 21 days of ageing in vacuum or MAP. It was observed that after 21 days of ageing, $L^{*}$ values significantly changed during day 2, 4 and 6 of display period but remained higher in the samples ageing in MAP, then displayed compared to the one ageing in vacuum, then displayed. Once the samples were opened from packages and displayed in darkness, they were exposed to oxygen in the air. This exposure could be the possible explanation of the differences seen during display. In our study, it was observed that redness $\left(a^{*}\right)$ in colour was more stable in vacuum packaging during display. Our results are in agreement with those of Kim et al. [2010] who reported that $\mathrm{a}^{*}$ values of steaks packaged in high oxygen MAP decreased rapidly after 9 days of display; whereas steaks packaged in vacuum had no significant change in a* values during display. Findings from several studies have shown that the lower the oxygen (40\%) is, the more the colour is fine for consumers [Zakrys et al., 2008; Zakry-Waliwanderal et al., 2009]. The $b^{*}$ values between samples ageing in vacuum, then displayed and in samples ageing in MAP, then displayed were significantly different during day 2 of display after 7 days 
of ageing. In addition, the samples ageing in MAP, then displayed have showed an increase of $b^{*}$ values during display after 21 days of ageing. Several authors have reported that $\mathrm{b}^{*}$ values increased during storage in MAP compared to vacuum packaging [Cachaldora et al., 2013; Kim et al., 2014]. O'Sullivan et al. [2003] reported in their study that sensory panellists correlated $b^{*}$ value to the brown colour. It is generally well recognised that when $\mathrm{a}^{*}$ value (redness) decreases, the meat tends to be brown.

An increase in TBARS values during ageing was observed in this study. Soyer et al. [2010] similarly found out that oxidation (measured as TBARS) was significantly influenced by the duration of storage. In a related study, Ferioli et al. [2008] stated that the progressive increase in TBARS during storage as they saw in their study was a consequence of the fast peroxide formation and that it influenced the TBARS formation. In this study, no effect of interaction within treatment and ageing period was found on TBARS. However, we noted that oxidative stability was influenced by ageing as TBARS decreased with ageing. Packaging type also influenced TBARS values and it was more pronounced in MAP than in vacuum. The difference may partly be explained by the levels of oxygen within the two treatments at the beginning, and this was observed during ageing time. Our results are supported by findings from previous studies [Kang et al., 2014; Zakrys et al., 2008] who reported that lipid oxidation increased with increase in oxygen levels in MAP. Nam et al. [2003] also reported the increase of lipid oxidation in aerobically stored turkey breast. The oxygen was the most critical factor influencing lipid oxidation during storage in this study. MAP packaged beef steaks had an increase in lipid oxidation during display based on the TBARS values after 14 days of ageing. Kim et al. [2010] also reported that high oxygen MAP packed beef had an increase in lipid oxidation based on TBARS values during display in contrast to steak packed in vacuum which did not change during display time.

The peroxide value increased significantly in this study in the samples packed in vacuum or MAP then displayed during the display period after different ageing time. However, PV remained low at all the ageing times and during display time. No interaction within treatment and ageing period was found on PV in this study. These results could be explained by the quick reaction of peroxides to form secondary byproducts. Olsen et al. [2005] also reported with respect to the peroxide value results from pork back fat, that hydroperoxides decomposed to secondary oxidation products at a faster rate than new hydroperoxides were formed. Nollet \& Todra [2009] explained using the redox reaction that the use of hydroperoxides as an indicator of lipid oxidation is limited because of their transitory nature.

A Pearson correlation analysis was used to determine if there is any correlation between colour parameters and lipid oxidation parameters (TBARS, PV) during storage. Our results have demonstrated that significant correlations between MAP- and vacuum-packed samples were found between colour parameters ( $\mathrm{L}^{*}$ and $\mathrm{a}^{*}$ values) and lipid oxidation parameter (TBARS). This could be explained by the fact that TBARS values increased during storage while the colour sta- bility -mainly reflected by $\mathrm{a}^{*}$ value - decreased. On the other hand, lipid oxidation has shown to influence colour stability.

\section{CONCLUSIONS}

The results of the present study indicate that colour attributes and lipid oxidation are influenced by packaging type, ageing and display time. Vacuum packaging has been found to maintain higher $\mathrm{a}^{*}$ values which are related to redness during 7, 14, 21 days ageing compared to MAP but generally resulted in lower $\mathrm{L}^{*}$ values. Furthermore, results have demonstrated that vacuum packaging preserves the colour stability better than MAP when displayed after different ageing times. Lastly, lipid oxidation has been found to be correlated with meat colour.

\section{RESEARCH FUNDING}

The authors would like to thank for the financial support from Chinese Government Scholarship, the "Agricultural Science and Technology Innovation Program" and the "Special Fund for Agro-scientific Research in the Public Interest (201303083)" in China.

\section{ACKNOWLEDGEMENTS}

The authors express appreciation to Benjamin J. Averitt, research assistant from Virginia Polytechnic Institute and State University, USA for his help on language editing.

\section{CONFLICT OF INTERESTS}

Authors declare no conflict of interests.

\section{REFERENCES}

1. Akoh C.C., Min D.B., Food Lipids: Chemistry, Nutrition and Biotechnology. 2008. Lipid Oxidation of Muscle Food, Third edn. CRC Press, Taylor and Francis Group, pp. 322-347.

2. AMSA, Meat color measurement guidelines. 2012, Champaign, Illinois USA: American Meat Sciences Association.

3. Beriain M.J., Goñi M.V., Indurain G., Sarriés M.V., Insausti K., Predicting longissimus dorsi myoglobin oxidation in aged beef based on early post mortem colour measurements on the carcass as a colour stability index. Meat Sci., 2009, 81, 439-445.

4. Botsoglou N.A., Fletouris D.J., Papageorgious G.E., Vassilopoulos V.N., Mantis A.J., Trakatellis A.G., Rapid, sensitive and specific thiobarbituric acid method for measuring lipid peroxidation in animal tissue, food and feedstuff sample. J. Agric. Food Chem., 1994, 42, 1931-1937.

5. Cachaldora A., García G., Lorenzo J.M., García-Fontán M.C., Effect of modified atmosphere and vacuum packaging on some quality characteristics and the shelf-life of "morcilla", a typical cooked blood sausage. Meat Sci., 2013, 93,220-225.

6. Esmer O.K., Irkin R., Degirmencioglu N., Degirmencioglu A., The effects of modified atmosphere gas composition on microbiological criteria, color and oxidation values of minced beef meat. Meat Sci., 2011, 88, 221-226. 
7. Faustman C., Sun Q., Mancini R., Suman S.P., Myoglobin and lipid oxidation interactions: Mechanistic bases and control. Meat Sci., 2010, 86, 86-94.

8. Ferioli F., Caboni M.F., Dutta P.C., Evaluation of cholesterol and lipid oxidation in raw and cooked minced beef stored under oxygen-enriched atmosphere. Meat Sci., 2008, 80, 681-685.

9. Gheisari H., Eskandari M., Effect of curing on camel meat lipid oxidation and enzymatic activity during refrigerated storage. Vet. Arhiv., 2013, 83, 551-562.

10. Hęśs M., Protein-lipid interactions in different meat systems in the presence of natural antioxidants - a review. Pol. J. Food Nutr. Sci., 2017, 67, 5-17.

11. Insausti K., Beriain M.J., Purroy A., Alberti P., Lizaso L., Hernandez B., Colour stability of beef from different Spanish native cattle breeds stored under vacuum and modified atmosphere. Meat Sci., 1999, 53, 241-249.

12. Jakobsen M., Bertelsen G., Colour stability and lipid oxidation of fresh beef. Development of a response surface model for predicting the effects of temperature, storage time, and modified atmosphere composition. Meat Sci., 2000, 54, 49-57.

13. Jeong J.Y., Claus J.R., Color stability of ground beef packaged in a low carbon monoxide atmosphere or vacuum. Meat Sci., 2011, 87, 1-6.

14. Kang S. M., Kang G., Seong P-N., Park B., Cho S., Evaluation of various packaging systems on the activity of antioxidant enzyme, and oxidation and color stabilities in sliced Hanwoo (Korean Cattle) beef loin during chill storage. Asian-Aust. J. Anim. Sci., 2014, 27, 1336-1344.

15. Kim D.S., Song Y.R., Lee S-J., Lee J.K., Lee K.S., Effects of gas composition in the modified atmosphere packaging on the shelflife of longissimus dorsi of Korean native black pigs-duroc crossbred during refrigerated storage. Asian-Aust. J. Anim. Sci., 2014 27, 1157-1163.

16. Kim Y. H., Huff-Lonergan E., Sebranek J.G., Lonergan S.M., High-oxygen modified atmosphere packaging system induces lipid and myoglobin oxidation and protein polymerization. Meat Sci., 2010, 85, 759-767.

17. Li X., Babol J., Bredie W.L., Nielsen B., Tománková J., Lundström K., A comparative study of beef quality after ageing longissimus muscle using a dry ageing bag, traditional dry ageing or vacuum package ageing. Meat Sci., 2014, 97, 433-442.

18. Li X., Lindahl G., Zamaratskaia G., Lundström K., Influence of vacuum skin packaging on color stability of beef longissimus lumborum compared with vacuum and high-oxygen modified atmosphere packaging. Meat Sci., 2012, 92, 604-609.

19. Li Y., Liu S., Reducing lipid peroxidation for improving colour stability of beef and lamb: on-farm considerations. J. Sci. Food Agric., 2012, 92, 719-726.
20. Lindahl G., Colour stability of steaks from large beef cuts aged under vacuum or high oxygen modified atmosphere. Meat Sci., 2011, 87, 428-435.

21. Mancini R. A., Hunt M.C., Current research in meat color. Meat Sci., 2005, 71, 100-121.

22. Marcos B., Aymerich T., Guardia M.D., Garriga M., Method in assessment of high hydrostatic pressure and starter culture on the quality properties of low-acid fermented sausages. Meat Sci., 2007, 76, 46-53.

23. Nam K.C., Ahn D.U., Combination of aerobic and vacuum packaging to control lipid oxidation and off-odor volatiles of irradiated raw turkey breast. Meat Sci., 2003, 63, 389-395.

24. Nollet L. M. L., Toldra F., Handbook of Processed Meats and Poultry Analysis. 2009. Determination of Oxidation, CRC Press. Taylor \& Francis Group, pp. 141-157.

25. O'Sullivan M.G., Byrne D.V., Martens H., Gidskehaug L.H., Evaluation of pork colour : prediction of visual sensory quality of meat from instrumental and computer vision methods of colour analysis. Meat Sci., 2003, 65, 909-918.

26. Olsen E., Vogt G., Ekeberg D., Sandbakk M., Petterson J., Nilsson A., Analysis of the early stages of lipid oxidation in freezestored pork back fat and mechanically recovered poultry meat. J. Agri. Food Chem., 2005, 53, 338-348.

27. Shantha N.C., Decker E.A., Rapid, sensitive iron-based spectrophotometric methods for determination of peroxide values of food lipids. J. Am. Oil Chem. Soc., 1994, 77, 421-424.

28. Soyer A., Ozalp B., Dalmıs U., Bilgin V., Effects of freezing temperature and duration of frozen storage on lipid and protein oxidation in chicken meat. Food Chem., 2010, 120, 1025-1030.

29. Strydom P.E., Hope-Jones M., Evaluation of three vacuum packaging methods for retail beef loin cuts. Meat Sci., 2014, 98, 689-694.

30. Vitale M., Pérez-Juan M., Lloret E., Arnau J., Realini, C. E. Effect of aging time in vacuum on tenderness, and color and lipid stability of beef from mature cows during display in high oxygen atmosphere package. Meat Sci., 2014, 96, 270-277.

31. Zakrys P.I., Hogan S.A., O'Sullivan M.G., Allen P., Kerry J.P., Effects of oxygen concentration on the sensory evaluation and quality indicators of beef muscle packed under modified atmosphere. Meat Sci., 2008, 79, 648-655.

32. Zakrys-Waliwander P.I., O'Sullivan M.G., Walsh H., Allen P., Kerry J.P., Sensory comparison of commercial low and high oxygen modified atmosphere packed sirloin beef steaks. Meat Sci., 2011, 88, 198-202.

Submitted: 7 June 2016. Revised: 19 February 2017. Accepted: 24 March 2017. Published on-line: 12 July 2017. 
